\title{
EJSBS
}

The European Journal of Social \&

Behavioural Science

ISSN-2301.2218 (ONUNE
OPEN ACCESS

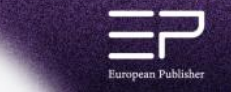

The European Journal of Social and Behavioural Sciences

EJSBS Volume 31, Issue 1 (eISSN: 2301-2218)

\section{VALUE ORIENTATIONS AS A FACTOR IN THE DEVELOPMENT OF IDEAS ABOUT MARRIAGE AMONG ADOLESCENT WOMEN}

\author{
Svetlana Vasilevna Merzlyakova ${ }^{a *}$ (iD, Marina Gerasimovna Golubeva ${ }^{\mathrm{b}}$ () \\ ${ }^{a}$ Department of General and Cognitive Psychology, Astrakhan State University, Tatishcheva St. 20a, Astrakhan, Russia, 414056 \\ ${ }^{b}$ Department of English for Humanities, Astrakhan State University, Tatishcheva St. 20a, Astrakhan, Russia, 414056
}

\begin{abstract}
The scientific novelty of this research is to identify the influence of the structure of valuable orientations on the formation of ideas about marriage among adolescent female students. The cross-sectional study involved 419 Caucasian young women aged between 17 to 19 years. Research methods included a bibliographic search, the application of several psych-diagnostic tests, and mathematical and statistical data analysis procedures. The results showed that the idea of an ideal wife is characterized by contradictory elements of cognitive and behavioral components among young women with a focus on gnostic and aesthetic values. The established mismatch in the content of the images "Ideal wife" and "I am a future wife" contributes to the development of intrapersonal conflict in the marital sphere for adolescent female students focused on the values of professional self-realization or gnostic-aesthetic values. Ideas about marriage in a group of young women with a focus on the values of personal life differ in the completeness of the formation of the cognitive component. The results show that youth (from 17 to 19 years) is a sensitive period to form complete and harmonious ideas about marriage through the development of family values among young women.
\end{abstract}

Keywords: Ideas about marriage, valuable orientations, adolescent female students

(C) 2022 Published by European Publisher. www.EuropeanPublisher.com

${ }^{*}$ Corresponding author.

E-mail address: svetym@yandex.ru

doi: $10.15405 /$ ejsbs.311

c) $($ This work is licensed under a Creative Commons Attribution-NonCommercial-NoDerivatives 4.0 International License. 
https://doi.org/10.15405/ejsbs.311

eISSN: 2301-2218 / Corresponding Author: Svetlana Vasilevna Merzlyakova

Selection \& Peer-review under responsibility of the Editors

\section{Introduction}

There is an increasing tendency of a number of negative influences that heighten the risk of causing a family demographic crisis within the socio-economic transformations of modern society which constitute an objective component of the social aspect of personality development. Some of these legalization of same-sex marriage as well as the imposition of LGBT community values, the promotion of ideas related to gender inclusiveness and gender reassignment can have a destructive informational impact on young people in their adolescence as the age group most sensitive to the social changes taking place in society.

This period of youth combines adolescence and early adulthood. Karabanova (2018) notes that each age stage is characterized by the social development of that particular age stage, characterized by development tasks that set the development vector which include a system of activities headed by the leader and age-related psychological new growths.

The main psychosocial task at the stage of entering adulthood is to build identity (van Doeselaar et al., 2020; Zimmermann et al., 2015). Building close relationships is especially important for young people, particularly students. The development of moral feelings, awareness of the value of long-term friendship, social obligations, the development of the ability to entrust oneself to another person and remain faithful to these relationships, even if they require self-denial, contributes to the fact that the considered stage of ontogenesis becomes a sensitive period for the formation of values of love and friendship. Xia et al. (2018) note that the ability to build romantic relationships is a key development task in adolescence. Researchers have studied the influence of family context (family climate, parenting style) and interpersonal communication skills (assertiveness, positive engagement) on the development of romantic relationships at the stage of entering adulthood. The relationship between the family context and interpersonal communication skills in adolescence which determine the features of romantic relationships in adolescence has been established (Xia et al., 2018). An important social context for developing romantic relationship skills is relationships with parents and friends. In a 12 year longitudinal study, Boisvert and Poulin (2016) tracked the impact of family relationships (family cohesion, conflict between parents and children), peer relationships (peer sympathy, social isolation, close friendships, friendships with the opposite sex) on romantic relationship patterns of young people between the ages of 16 and 24 . They found and described romantic relationship patterns from adolescence to adulthood and examined their associations with family and peer experiences in early adolescence. Data from Kochendorfer and Kerns' (2017) longitudinal study show that parents and friends influence the beginning and quality of romantic relationships at the age of 12-15 years. The romantic relationships of modern youth were also found to be influenced by the experience of older brothers and sisters. The results of a study of young people aged 12 to 20 years showed that romantic competence increases over time among young men and young women who have older siblings of the opposite sex (Doughty et al., 2015). Younger siblings' relationship experiences over a 2-year period could be predicted through findings which reported on older siblings' involvement in a dating relationship, cohabitation, and engagement/marriage (Wheeler et al., 2016). Shulman et al. (2019) revealed four distinctive romantic pathways differing in stability and the ability to progress toward intimacy among youth from 16 to 23 years as follows: Sporadic and Casual Encounters, Sporadic Encounters in Response to a Stressful Romantic Experience; Steady Non-Intimate Involvements; and Steady Progression toward Intimate Involvements. Breaking up a romantic relationship is one of the most negative experiences in adolescence. Larson et al. (2016) state that the consequences of breaking up a romantic relationship are 
https://doi.org/10.15405/ejsbs.311

eISSN: 2301-2218 / Corresponding Author: Svetlana Vasilevna Merzlyakova

Selection \& Peer-review under responsibility of the Editors

manifested in depressive symptoms, maladaptation, deviant behavior up to the involvement of young people in crime (Larson et al., 2016). The results of O'Sullivan et al.'s (2019) study can be used in educational and counseling programs to support young people who are going through a breakup with a partner.

\section{Problem Questions}

One of the main and currently insufficiently studied areas in family psychology is the question of the conditions and factors that contribute to or hinder the formation of an emotional and semantic attitude towards assuming the role of a spouse and parent related to the psychological aspects of the sociodemographic problems of a modern young family. According to Galperin (2005), perceptions of marriage and family act as an indicative basis for the mastered activity, that is, marital and parental behavior (as cited in Zakharova et al., 2019). This theory was well illustrated by the results of a study that showed that exposure to violence between parents among adolescents was a key predictor of marital partner violence in their own family (Lohman et al., 2013).

The structure of ideas about marriage includes cognitive, emotional and behavioral components in the context of this research. The cognitive component is the image of oneself as a spouse and marriage partner, knowledge and understanding of marital functions, awareness of the qualities necessary for mastering the marital role and implementing marital behavior. The emotional component is a positive attitude towards family, marriage partner, future children, marital rights and responsibilities, and the need for a family lifestyle. The behavioral component focuses on awareness of the ways of implementing marital functions, the attitude towards active fulfilment of family responsibilities by the marriage partner (role expectations), readiness and ability to fulfil marital duties (role claims).

In the context of this research, we consider 'valuable orientations' as a personal factor in the formation of ideas about marriage among adolescent students. Valuable orientations in this context constitute the individual's orientation to certain values which are manifested in the features of goal-setting and ways of achieving these goals. The individual's valuable orientations operate on a complex dynamic structure that, on one hand, depends on the values of society, and on the other hand, is subject to regular changes in the process of ontogenesis and bears the imprint of individual differences. Valuable orientations are relatively stable, socially determined orientation of an individual to life goals and ways of achieving them, determined by intrapersonal formations.

One of the main functions of valuable orientations is to regulate behavior; to choose a conscious action in certain social conditions. At the same time, each of the valuable orientations makes a "contribution" to the overall organization of activities. Such decisions are made regarding the type of behavior and the direction of an activity by choosing certain values. Lomov (2000) notes that valuable orientations act as a kind of backbone of the subjective world of the personality. Some certain habits, behavioral stereotypes, ways of interacting with other people are formed in the process of their development - the style of behavior of the personality as a whole (as cited in Kulikov, 2000, p. 110).

Zdravomyslov (1986) consider the main function of valuable orientations to be "the regulation of behavior as a conscious action in certain social conditions" (p. 46). Yadov (1970) argues that the mental regulation of social activity or the behavior of a subject in a social environment is the most important function of the dispositional system. Behavior operates on a rather complex structure including behavioral 
acts (a specific reaction of a subject to an actual subject situation), a habitual action or act (an elementary socially significant "unit" of behavior), behavior in a particular field of activity (a sequence of actions) and, finally, holistic behavior or activity in its entirety. According to Yadov (1970), at all levels the behavior of a personality is regulated by its dispositional system; however, in each specific situation and depending on the goal, the leading role belongs to a certain dispositional education. It becomes clear that the role of valuable orientations in regulating human behavior is of fundamental importance, since it is these orientations that set the axiological vector of an individual's life activity as a whole and globally guide his or her behavior.

Thanks to the worldview, beliefs, attitudes, character, etc., the personality does not act as an object of external influences, but as a force that actively transforms the circumstances of the external world. Thus, value orientations have a decisive influence on the activity and behavior of the personality

\section{Research Questions}

i. To identify differences (if any) in perceptions of marriage depending on the structure of students' valuable orientations in adolescence.

ii. To identify the age period of student life which is the most sensitive for the formation of complete and harmonious ideas about marriage among adolescent young women?

\section{Purpose of the Research}

The purpose of the study is to identify the features of ideas about marriage among adolescent female students with different structure of valuable orientations.

\section{Research Methods}

The bibliographic method involved a comprehensive analysis of domestic and foreign psychological and pedagogical scientific literature on the main research problems.

The psycho-diagnostic method included the application of the following instruments: "A Value and Availability Ratio in Various Vital Spheres Technique" questionnaire developed by Fantalova (2001), the Semantic Differential method developed by Charles E. Osgood (as cited in Solomin, 2011), the Projective Technique of "Incomplete Sentences" (Raigorodsky, 2001), and the "Role Expectations and Claims in Marriage” questionnaire developed by Volkova (Volkova \& Trapeznikova, 2012).

The mathematical and statistical procedures used to analyze the data included cluster analysis (Kmeans method), Kolmogorov-Smirnov test for one sample, Shapiro-Wilkes criterion, and correlation analysis.

The study involved 419 female students from Astrakhan universities between the ages of 17 to 19 years old. A stratometric selection strategy was employed involving randomization with the allocation of strata depending on the gender and age of students. The research was in the Astrakhan State University in Russia.

Participation in the study was voluntary and did not involve remuneration nor were individual results revealed to the sample. Respondents filled out pencil and paper questionnaires. One of the co-authors of 
https://doi.org/10.15405/ejsbs.311

eISSN: 2301-2218 / Corresponding Author: Svetlana Vasilevna Merzlyakova

Selection \& Peer-review under responsibility of the Editors

this paper, Professor Merzlyakova conducted the survey and data collection in 2020. The return rate was $100 \%$.

\section{Findings}

\subsection{Determination of the structure of valuable orientations among young women in adolescence}

We determined the hierarchy of values of students using the questionnaire "A Value and Availability Ratio in Various Vital Spheres Technique" by Fantalova (2001). Three homogeneous clusters were identified as a result of divisive clustering of the sample. The first cluster - "orientation to the values of professional self -realization" included $61(14.6 \%)$ young women for whom the values of active life, interesting work, financially secure life, self-confidence, freedom as independence in acts and actions are significant. The second cluster - "orientation to gnostic and aesthetic values" - consisted of 94 (22.4\%) young women who differ in the significance of such values as knowledge, creativity, the beauty of nature and art. The third cluster - "orientation to the values of personal life" - includes 264 (63\%) young women for whom a happy family life, love, health, and the presence of good and loyal friends are highly significant.

Further, using correlation analysis, we identified the content characteristics of ideas about marriage among the young women with different valuable orientations structure. The Pearson linear correlation (r) for quantitative variables, the distribution of which corresponds to the normal law, and the Spearman rank correlation (rs), meaningful characteristics of ideas about marriage were revealed depending on the valuable orientations structure among young women. The ranking procedure by the amount of the correlation coefficient at the level of statistical significance allowed us to establish a hierarchy of meaningful characteristics among the young women's perception of marriage.

\subsection{Perception of an ideal husband among the young women with different valuable orientations structure}

For the young women who are focused on the values of professional self-realization (figure 1), the image "Ideal husband" contains 12 characteristics with the following hierarchical structure: 1) caring; 2) respect for others; 3) role expectations parental educational sphere; 4) positive attitude towards family recreation and leisure time; 5) positive attitude about future marriage partner; 6) personal independence; 7) balance; 8) positive attitude towards family as a social institution; 9) successfulness; 10) industriousness; 11) empathy; 12) underestimation of intimate sexual relations in marriage. 


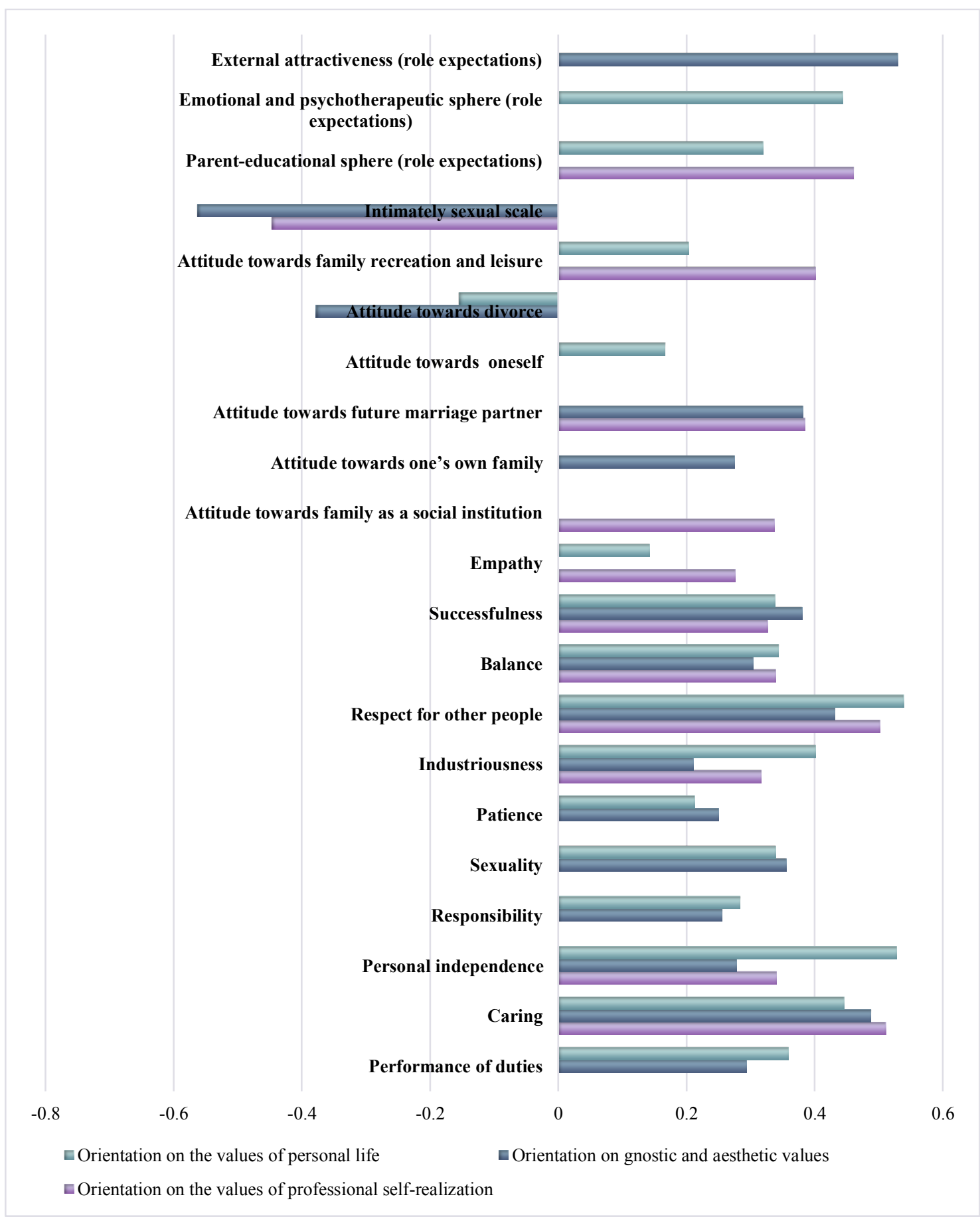

Figure 1. The content of the perception of an ideal husband among the young women with different valuable orientations structure, correlation coefficient

For the young women who are focused on gnostic and aesthetic values, the image of the "Ideal husband" comprises 15 elements of cognitive, emotional and behavioral components, which have the following hierarchy: 1) external attractiveness; 2) caring; 3 ) respect for others; 4) a positive attitude towards future marriage partner; 5) successfulness; 6) sexuality; 7) balance; 8) performance of duties; 9) personal independence; 10) a positive attitude towards one's own family; 11) responsibility; 12) patience; 13) industriousness; 14) negative attitude towards divorce; 15) underestimation of intimate sexual relations in marriage. 
Young women who are focused on the values of their personal life have the greatest number of meaningful characteristics about the ideal spouse. The image of "Ideal husband" includes 16 elements of cognitive, emotional and behavioral components, forming the following hierarchy: 1) respect for others; 2) personal independence; 3) caring; 4) role expectations in an emotionally-psychotherapeutic field; 5) industriousness; 6) performance of duties; 7) balance; 8) sexuality; 9) successfulness; 10) role expectations parental educational sphere; 11) responsibility; 12) patience; 13) positive attitude towards family recreation and leisure time; 14) positive attitude towards oneself; 15) empathy; 16) negative attitude towards divorce.

\subsection{Perception of an ideal wife among young women with different valuable orientations structure}

For young women who are focused on the values of professional self-realization, the image of the "Ideal wife" consists of fewer meaningful characteristics than the image of the "Ideal husband". Figure 2 demonstrates that the perception of ideal wife comprises 7 elements of cognitive and behavioral components with the following hierarchy: 1) role claims in the sphere of social activity; 2) industriousness; 3) personal identification with the spouse; 4) personal independence; 5) successfulness; 6) caring; 7) underestimation of intimate sexual relations in marriage.

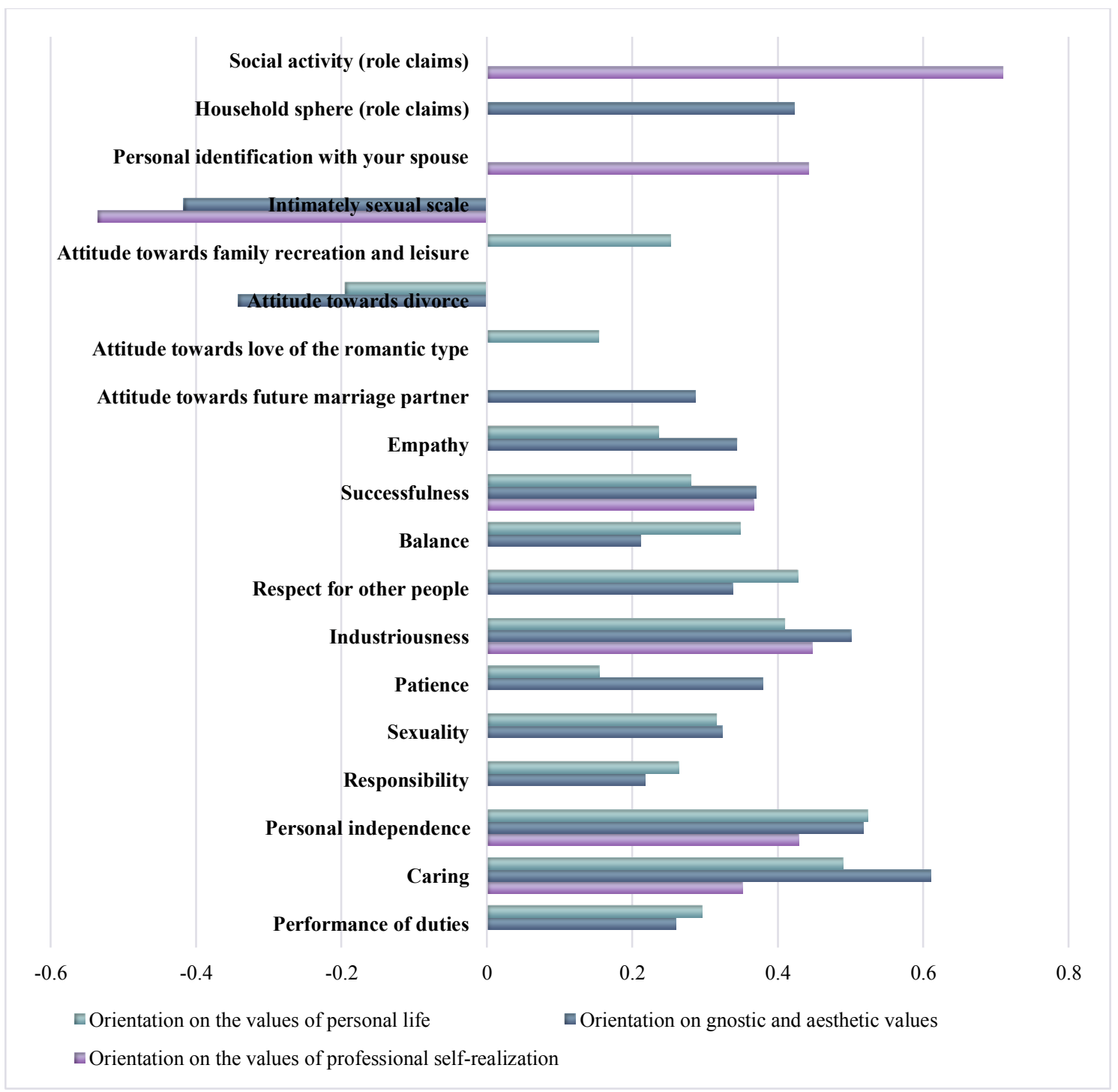

Figure 2. Perception of an ideal wife among young women with different valuable orientations structure, correlation coefficient 
For young women who are focused on gnostic and aesthetic values, the image of the "Ideal wife" comprises 15 meaningful characteristics with the following hierarchical structure: 1) caring; 2) personal independence; 3 ) industriousness; 4) role of claims in the household sphere; 5) patience; 6) successfulness; 7) empathy; and 8) respect for others; 9) sexuality; 10) positive attitude towards future marriage partner; 11) performance of duties; 12) responsibility; 13) balance; 14) negative attitude towards divorce; 15) underestimation of intimate sexual relations in marriage.

In the group of young women with orientation on values of personal lives, in comparison with the image of the "Ideal husband", fewer meaningful characteristics emerged for the perception of an ideal wife. The image of the "Ideal wife" has 14 items of the cognitive and affective components: 1) personal independence; 2) caring; 3 ) respect for others; 4) industriousness; 5) balance; 6) sexuality; 7) performance of duties; 8) successfulness; 9) responsibility; 10) positive attitude towards family recreation and leisure time; 11) empathy; 12) patience; 13) positive attitude towards love of the romantic type; 14) negative attitude towards divorce.

\subsection{Perception of self-image as a future wife among young women with different valuable orientations} structure

In the group of young women with a focus on the values of professional self-realization, the image of "I am a future wife" revealed an increase in the number of content characteristics and the emotional component is updated (figure 3). The image of "I am a future wife" includes 10 content characteristics with the following hierarchy: 1) role claims in the sphere of social activity; 2) positive attitude towards family as a social institution; 3) positive attitude towards romantic love; 4) balance; 5) respect for others; 6) positive attitude about future marriage partner; 7) empathy; 8) caring; 9) patience; 10) underestimation of intimate sexual relations in marriage. In comparison with the image of "Ideal wife", the image of "I am a future wife" lacks such qualities as industriousness, personal independence, successfulness, and the importance of caring, intimacy and sexual sphere is reduced. With regard to the perception of future marriage, young women revealed additional elements of cognitive (balance, respect for other people, empathy, patience) and emotional (positive attitude towards the family as a whole, romantic love, a future marriage partner) components. 


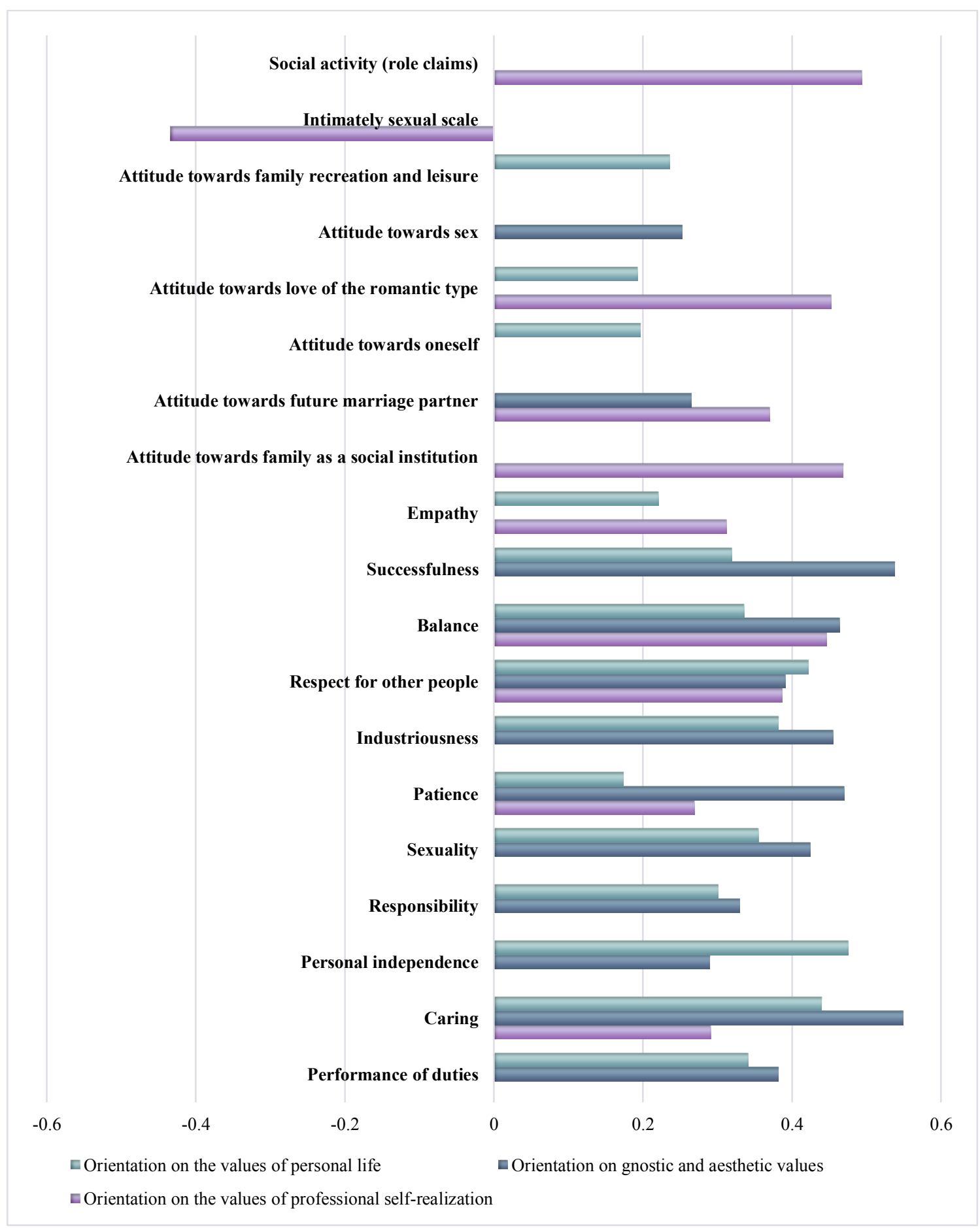

Figure 3. Perception of the image of "I am a future wife" among young women with different valuable orientations structure, correlation coefficient

Among young women with an orientation on gnostic and aesthetic values, the image of "I am a future wife" contains 12 elements of cognitive and emotional components: 1) caring; 2) successfulness; 3) patience; 4) balance; 5) industriousness; 6) sexuality; 7) respect for others; 8) performance of duties; 9) responsibility; 10) personal independence; 11) positive attitude about future marriage partner; 12) positive attitude towards sex. The image of "I am a future wife" revealed the importance of such personal qualities as successfulness, patience, balance, sexuality, respect for other people, performance of duties, and increased responsibility. At the same time, the role of personal independence, industriousness, and a 
positive attitude towards future marriage partner showed a decrease. There is no empathy, negative attitude to divorce, or elements of behavioral component in the perception of future marriage in comparison with the image of "Ideal wife".

Among young women with an orientation on values of personal lives, the characteristics of the image of "I am a future wife" practically coincide with the image of "Ideal wife" with a change in the hierarchy: 1) personal independence; 2) caring; 3) respect for others; 4) industriousness; 5) sexuality; 6) performance of duties; 7) balance; 8) successfulness; 9) responsibility; 10) positive attitude towards family recreation and leisure time; 11) empathy; 12) positive attitude towards oneself; 13) positive attitude towards love of the romantic type; 14) patience. In the image of "I am a future wife", the importance of sexuality and performing duties increases but the role of such personal qualities as balance and patience decreases. In the emotional component of this image, a positive attitude towards oneself appears while the negative attitude towards divorce disappears.

\section{Discussion}

This study has established that perceptions about marriage among young women aged 17 to 19 years are influenced by their valuable orientations structure. Common personal qualities in the image of "Ideal husband" are caring, respect for other people, personal independence, balance, successfulness, and industriousness. If these cognitive component elements are common, invariant characteristics of the perceptions about the future marriage partner related to the content of the emotional and behavioral components are determined by their valuable orientations. Those young women with a focus on the values of professional self-realization, the image of "Ideal husband" is complemented by empathy, a positive attitude towards family recreations and leisure, towards a future marriage partner, towards family as a social institution, parental and educational responsibilities, and insignificant sexual relations in marriage. For those young women focused on gnostic-aesthetic values or values of personal life, their image of "Ideal husband" had additional elements of cognitive (sexuality, performance of duties, responsibility, patience) and emotional (negative attitude towards divorce) components. Young women with a focus on gnostic and aesthetic values' perception of an ideal husband differs in the presence of elements of emotional (positive attitude towards their own family, towards future marriage partner) and behavioral (underestimation of intimate and sexual relations in marriage, external attractiveness) components. In this group of young women, a contradiction in the image of "Ideal husband" is noticeable between the elements of the cognitive and behavioral components. The cognitive component sexuality occupies the sixth rank, which is reflected by the insignificant emphasis in the behavioral component of intimate-sexual relations between spouses. The perception of image of "Ideal husband" among young women with a focus on the values of personal life also revealed empathy, additional elements of emotional (positive attitude towards oneself, towards family recreation and leisure) and behavioral components (role expectations in the emotional and psychotherapeutic sphere, that is, the desire to provide moral and emotional support to family members; role expectations in the parental and educational sphere, that is, the active parental position of the marriage partner, the desire to perform parental duties). Such an orientation to the image of their own father in their perception of the ideal husband appears only in this typological group of young women.

In the image of "Ideal wife", the common personal qualities that emerged are personal independence, caring, industriousness, and successfulness. In addition, the invariant characteristic is shown 
by the finding that the mother is a guide in forming ideas about marital behavior (Ideal wife, I am a future wife) for young women between the ages of 17 and 19. Modern young women in their adolescence tend to idealize a future marital role. The image of "Ideal wife" is characterized by the presence of such elements of the behavioral component as role claims in the sphere of social activity, the installation of personal identification with the spouse, underestimation of intimate and sexual relations in marriage for young women who are focused on the values of professional self-realization. Young women who are focused on gnostic-aesthetic values or values of personal life have common content characteristics in the image of "Ideal wife": respect for other people, sexuality, patience, balance, empathy, performance of duties, responsibility, negative attitude towards divorce. Among this group of young women, the idea of an ideal wife is supplemented by elements of an emotional (positive attitude towards future marriage partner) and behavioral (role claims in the household sphere, that is, the installation of their own active participation in household management; underestimation of intimate and sexual relations in marriage) component. The contrast is very clear in image of "Ideal wife" among these young women between the elements of cognitive (sexuality is an important quality and occupies the ninth rank) and behavioral (low importance of intimatesexual relations between spouses) components. For young women focused on the values of personal life, the image of "Ideal wife" is characterized by a positive attitude towards family recreation and leisure, and towards romantic love.

For young women with a focus on the values of professional self-realization, the image of "I am a future wife" differs from the image of "Ideal wife" in a large number of content characteristics and the presence of elements of the emotional component. There is a clear comparison among the young women focused on gnostic and aesthetic values in their perceptions of the images of "ideal wife" and "I am a future wife". The number of content characteristics is reduced and there is no behavioral component. For young women focused on the values of their personal life, the content characteristics of the images of "I am a future wife" largely coincide with that of "Ideal wife", but their hierarchy changes. Thus, there are multidirectional trends in the formation of ideas about the future marital role among young women depending on the system of valuable orientations. There is a discrepancy among young women focused on the values of professional self-realization or gnostic-aesthetic between theoretical stereotypical ideas about what the ideal wife should be and their practical application in the image of "I am a future wife". There is an increased risk of intrapersonal conflict in the marital sphere which can become either a source of formation of various complexes or an area of immediate personal development. It should be noted that the perceptions of "ideal husband" have a greater number of content characteristics compared to the ideas about the marital role of the wife ("Ideal wife", "I am a future wife"). Consequently, in adolescence, young women are more likely to have attitudes, role expectations, and requirements for a future marriage partner than for themselves.

A comparative analysis of the content of ideas about marriage in adolescence and early adulthood indicates that age dynamics are characterized by the heterochronous formation of the constituent components of ideas about marriage in female students with different valuable orientations structures. The greatest originality of the emotional and behavioral components differs in the idea of marriage in adolescence. For adolescent young women with a focus on the values of professional self-realization, the image of "Ideal husband" reveals elements of cognitive, emotional and behavioral components. Earlier research in this area has shown that the idea of an ideal husband in early adulthood is limited to the content 
characteristics of the cognitive and emotional components (Merzlyakova \& Golubeva, 2021). If in adolescence the ideas of an ideal wife among young women have elements of cognitive and behavioral components, then in early adulthood, only the cognitive component is formed. The image of "I am a future wife" in adolescence shows elements of the cognitive, emotional and behavioral components, whereas in early adulthood, the content characteristics of the cognitive and emotional components remain. In adolescence young women with a focus on gnostic and aesthetic values, the image of "Ideal husband" contains elements of the cognitive, emotional and behavioral components, but in early adulthood, only the cognitive component of ideas about the marital role is formed. The image of "Ideal wife" shows elements of cognitive, emotional and behavioral components in adolescence and early adulthood. If in adolescence the image of "I am a future wife" contains elements of the cognitive and emotional components, then in early adulthood, there are substantial characteristics of the cognitive and behavioral components. Among adolescent young women with a focus on the values of personal life, the image of "Ideal husband" is characterized by the presence of elements of cognitive, emotional, and behavioral components in adolescence and early adulthood. The image of "Ideal wife" consists of meaningful characteristics of the cognitive and emotional components in adolescence, and in early adulthood, the behavioral component of ideas about marriage is additionally updated. In the image of "I am a future wife", a cognitive and emotional component is formed in adolescence and early adulthood. The obtained results indicate that the period of youth (from 17 to 19 years) is a sensitive period for the formation of complete and adequate ideas about the marital role, and education of family values as shown among the sampled female students in this study.

Within the framework of the academic discipline "Psychology of Family Self-determination" (Merzlyakova \& Golubeva, 2019), two meaningful lines of work with students were designed: a theoretical information block and practical activities. In order to optimize the development of the cognitive component of ideas about marriage, a theoretical information block is needed, which involves considering the concept of marriage and the main characteristics of marital relations. In order to optimize the process of assimilation of the proposed theoretical information, several activities were offered to students:

- to record in writing the qualities that an ideal husband / wife should have (individual work);

- to agree in a subgroup on a single list of personality traits of an ideal husband / wife to be presented in a compact group (work in microgroups);

- to formulate, discuss and coordinate all group proposals in order to develop a single list of personality traits of an ideal husband / wife on the basis of this at the general team plenum.

In order to develop family values among students, a follow-up practical activity was provided:

- students are requested to form 3 subgroups and assemble a mosaic of family values: 1) the values of marriage (the value of marriage, the value of the equality of the spouses, the value of the dominating one of them, the value of different gender roles in the family, the value of interpersonal communication between spouses, relations of mutual support and understanding among spouses); 2) the value associated with parenthood (the value of children, including the value of large family or family with few children as well as the value of education and socialization of children in the family); 3) the value associated with the relationship (the value of the presence of family members, such as brothers and sisters; the value of cooperation and mutual support between family members; the value of extended or nuclear family); 
- participants need to draw a "Family Values Tree" on the sheet of paper, which should be depicted in such a way that your basic, most fundamental values become the roots of the tree, the trunk is slightly less important, and the branches represent those values that are important, but not so fundamental for you;

- students, first in a circle, describe the image of an ideal family in which everyone understands each other, perhaps indicate the main functions of family members, emphasizing their importance for the whole family. Then the group offers a list of 5 to 10 family values, which will be arranged in order of their importance. The values are recorded by the teacher on the watman paper and discussed. Then the group is divided into 3 - 4 subgroups, each of which chooses its own value and "builds" its image, a group sculpture (it is desirable that all participants participate in its construction). Thus, we get several sculptures of family values, each of which can move and speak. It is important that participants can show the importance of each value in the life of family members. At the next stage, it is possible to build a common sculpture of family values, which ultimately should become a sculpture of family values. It is important that all the "values" are in one sculpture find a common ground and "get along" together.

In our opinion, the implementation of the above practical tasks involves the transformation of the acquired knowledge in the discipline "Psychology of Family Self-determination" into practical skills and will have a positive impact on the development of emotional and behavioral components of ideas about marriage among modern students.

\section{Conclusion}

This study reveals that such personal factors as the structure of valuable orientations determines the specifics of ideas about marriage among adolescent young women. This study has proposed as reference points the social roles of the spouses ("Ideal husband", "Ideal wife", "I am a future wife") based on which, young women will be able to build their own marital behavior in the future. The concepts of marriage have both common and specific features according to the influence of the structure of valuable orientations. The lack of purposeful work on the formation of the younger generation's readiness for marriage characterizes the fragmentation and, in some cases contradictory, of formation of emotional and behavioral components, as seen in the images of "Ideal husband/wife" of young women with a focus on the gnostic and aesthetic values in adolescence. The discrepancy of structural and content characteristics in the images of "Ideal wife" and "future wife" revealed in adolescence indicates a possible intrapersonal conflict in the marital sphere among young women which can become a mechanism for the formation of family self-determination at this stage of age development. The obtained results indicate that the period of youth (from 17 to 19 years) is a sensitive period for psychological and pedagogical influence on the process of family selfdetermination of students, the formation of complete and adequate ideas about the marital role, and the education of family values among adolescent female students.

\section{Acknowledgements}

The research was carried out with the financial support of the Russian Foundation for Basic Researches (RFBR) in the framework of scientific project № 20-013-00072 "Personal Factors of Family Self-determination Development in Adolescence and Early Adulthood".

The author(s) declare that there is no conflict of interest. 


\section{References}

Boisvert, S., \& Poulin, F. (2016). Romantic Relationship Patterns from Adolescence to Emerging Adulthood: Associations with Family and Peer Experiences in Early Adolescence. Journal of Youth and Adolescence, 45, 945-958. https://doi.org/10.1007/s10964-016-0435-0

Doughty, S. E., Lam, C. B., Stanik, C. E., \& McHale S. M. (2015). Links Between Sibling Experiences and Romantic Competence from Adolescence Through Young Adulthood. Journal of Youth and Adolescence, 44, 2054-2066. https://doi.org/10.1007/s10964-014-0177-9

Fantalova, E. B. (2001). Diagnostics and psychotherapy of internal conflict. Samara.

Galperin, P. Y. (2005). Lectures on psychology: textbook for University students. Moscow Psychology and Social Institute.

Karabanova, O. A. (2018). Development of Age and Psychological Approach in Modern Psychology. RAS Institute of Correctional Pedagogics, 35, 1-13.

Kochendorfer, L. B., \& Kerns, K. A. (2017). Perceptions of Parent-Child Attachment Relationships and Friendship Qualities: Predictors of Romantic Relationship Involvement and Quality in Adolescence. Journal of Youth and Adolescence, 46, 1009-1021. https://doi.org/10.1007/s10964-017-0645-0

Kulikov, L. V. (2000). Psychology of personality in the works of domestic psychologists. Piter.

Larson, M., Sweeten, G., \& Piquero, A. R. (2016). With or Without You? Contextualizing the Impact of Romantic Relationship Breakup on Crime Among Serious Adolescent Offenders. Journal of Youth and Adolescence, 45, 54-72. https://doi.org/10.1007/s10964-015-0318-9

Lohman, B. J., Neppl, T. K., Senia, J. M., \& Schofield, T. J. (2013). Understanding Adolescent and Family Influences on Intimate Partner Psychological Violence During Emerging Adulthood and Adulthood. Journal of Youth and Adolescence, 42, 500-517. https://doi.org/10.1007/s10964-013-9923-7

Merzlyakova, S. V., \& Golubeva, M. G. (2019). The Development of Family Self-determination of Student's Youth. European Proceedings of Social and Behavioral Sciences, 56, 395-403. https://doi.org/10.15405/epsbs.2019.02.02.43

Merzlyakova, S. V., \& Golubeva, M. G. (2021). Ideas about Marriage Depending on the Structure of Valuable Orientations of Women in Early Adulthood. Psychological Applications and Trends. 237241. https://doi.org/10.36315/2021 inpact049

O’Sullivan, L. F., Hughes, K., Talbot, F., \& Fuller, R. (2019). Plenty of Fish in the Ocean: How do Traits Reflecting Resiliency Moderate Adjustment After Experiencing a Romantic Breakup in Emerging Adulthood? Journal of Youth and Adolescence, 48, 949-962. https://doi.org/10.1007/s10964-01900985-5

Raigorodsky, D. Y. (Ed.). (2001). Practical Psych Diagnostics. Methods and Tests. Tutorial. Samara: Publishing House "BAKHRAKH-M», 672.

Shulman, S., Seiffge-Krenke, I., Ziv, I., \& Tuval-Mashiach, R. (2019). Patterns of Romantic Pathways among 23 Year Olds and their Adolescent Antecedents. Journal of Youth and Adolescence, 48, 1390-1402. https://doi.org/10.1007/s10964-018-0951-1

Solomin, I. L. (2011). Psychosemantic diagnosis of hidden motivation. Methodical manual. SPb.: IMATON, 112.

van Doeselaar, L., McLean, K. C., Meeus, W., Denissen, J. J. A., \& Klimstra, T. A. (2020). Adolescents' Identity Formation: Linking the Narrative and the Dual-Cycle Approach. Journal of Youth and Adolescence, 49, 818-835. https://doi.org/10.1007/s10964-019-01096-x

Volkova, A. N., \& Trapeznikova, T. M. (2012). Methodical Receptions of Diagnostics of Matrimonial Relations. Questions of psychology, 5, 110-116.

Wheeler, L. A., Killoren, S. E., Whiteman, S. D., Updegraff K. A., McHale, S. M., \& Umaña-Taylor A. J. (2016). Romantic Relationship Experiences from Late Adolescence to Young Adulthood: The Role of Older Siblings in Mexican-Origin Families. Journal of Youth and Adolescence, 45, 900-915. https://doi.org/10.1007/s10964-015-0392-z

Xia, M., Fosco, G. M., Lippold, M. A., \& Feinberg, M. E. (2018). A Developmental Perspective on Young Adult Romantic Relationships: Examining Family and Individual Factors in Adolescence. Journal of Youth and Adolescence, 47, 1499-1516. https://doi.org/10.1007/s10964-018-0815-8

Yadov, V. A. (1970). Interdisciplinary approach to the study of the relationship between value orientations and observed behavior. Moscow. 
Zakharova, E. I., Karabanova, O. A., Starostina, Y. A., \& Dolgikh, A. G. (2019). Ideas about the Future of Parenthood in Adolescence and Young Adulthood. Russian Psychological Journal, 2(16), 103-122. https://doi.org/10.21702/rpj.2019.2.6

Zdravomyslov, A. G. (1986). Needs, interests, and values. Politizdat.

Zimmermann, G., Lannegrand-Willems, L., Safont-Mottay, C., \& Cannard, C. (2015). Testing New Identity Models and Processes in French-speaking Adolescents and Emerging Adults Students. Journal of Youth and Adolescence, 44, 127-141. https://doi.org/10.1007/s10964-013-0005-7 